\title{
Organizational Enablers to the Governance of Collaborative University-Industry R\&D Programs
}

\author{
Gabriela Fernandes \\ CEMMPRE, Department of \\ Mechanical Engineering \\ University of Coimbra \\ Coimbra, Portugal \\ gabriela.fernandes@dem.uc.pt
}

\author{
Sara Leite \\ Department of Production and Systems \\ University of Minho \\ Guimarães, Portugal \\ sivl.7@hotmail.com \\ Ana Correia Simões \\ INESC TEC - Institute for Systems and \\ Computer Engineering, Technology \\ and Science \\ Porto, Portugal \\ ana.c.simoes@inesctec.pt
}

\author{
Madalena Araújo \\ ALGORITMI, Department of \\ Production and Systems \\ University of Minho \\ Guimarães, Portugal \\ mmaraujo@dps.uminho.pt
}

\begin{abstract}
Governance has a significant impact on the success of programs and projects. However, governance of collaborative university-industry projects and programs in literature, is a rather scarce topic. Based on an ethnographic study of a large university-industry collaboration, this paper proposes a conceptual framework of Organizational Enablers (OEs) to improve the governance of collaborative universityindustry R\&D programs. An exploratory research was carried out, aiming to learn from the experience of program and project managers and other program stakeholders of the case under study. Qualitative data was collected using participant observation and document analysis. The framework highlights nine OEs: 'Established governance policies and values', 'Formal Governance support structures', 'Flexible organization structures', 'Standardization of program and project management practices', 'Different management approaches to fit the project needs',' Clearly defined roles and responsibilities', 'Different means of communication and interaction', 'Top management Support' and 'Projects strategic alignment within the industry and university roadmaps'.
\end{abstract}

Keywords-Governance, University-industry, Collaborative programs and projects, Organizational Enablers

\section{INTRODUCTION}

University-industry collaboration has been a popular research area in the last years. There is significant increase in the number of publications that explore this theme from different perspectives, such as: motivations, factors that facilitate or inhibit its implementation, main activities and outcomes [1].

Due to a number of reasons, where the current challenges of circular economy plays a prominent role, collaborations between industries and universities have been stimulated by policy makers, with the aim of encouraging competitiveness and development [2]. These collaborations can be of various domains, such as: collaborative research projects, (e.g., joint research or research contracts, based on contracts between universities and industry); commercialization of Research and Development $(R \& D)$ results (e.g., intellectual property rights through patents); entrepreneurship (e.g., creation of spin-offs by students and academics; less commonly, professional mobility for a period of time from academia to industry and industry to academy; and finally, related more to education, such as joint curriculum design and delivery, student mobility and lifelong learning [3]. This paper focus on collaborative research projects.
University-industry collaborations have associated a set of advantages that are linked to the common and individual interests of the universities and industrial companies involved, as well as to the interests of society in general. Hence, the interest in establishing collaborations between the university and the industry, with reciprocal benefits for all the entities involved [4]. On one hand, universities support companies to improve their innovation capacities and their scientific knowledge through access to research and essential skills $[5,6]$. They also support companies in solving real problems $[7,8]$ and contribute to increase their reputation [6]. On the other hand, universities, by engaging in these collaborations, align the research internally developed to the needs of the industry, contributing to the national and regional economy and improving the academic reputation [9]. Universityindustry R\&D collaborations are increasingly based on the principle of symbiosis. That is, each party contributes, either university or industry, with its own particular strengths, in a joint effort to attain a common goal; the complementarity of those strengths would improve the aggregate performance of both parties [10]. Each entity has highly differentiated inputs, since the individual capabilities of each industry as well as the expertise of academic university researchers cannot be simply transferred. University-industry collaborations provide a set of advantages that contribute to the common and individual interests of university and industry's stakeholders involved, as well as to the interests of society in general [6].

Projects and programs are the main means by which organizations achieve strategic goals and beneficial changes, increasing their organizational value [11]. University-industry R\&D collaborations are usually funded and named as projects by public funding entities, but often are organized by partners as programs. A program is a set of projects whose objectives are related and aim at achieving a set of major benefits (synergies) that are more than just the sum of the projects they consist of [12]. A collaborative university-industry R\&D program is here defined as a temporary organization with a collaborative work environment, within a specific context, with heterogeneous partners, collective responsibilities and, in most cases, with public funding support [13].

Complexity and uncertainty are both attributes of programs [14]. Programs require a specific way of thinking, more uncertainty-tolerant, closer to change, and more aware of business influence; besides, the time of a program completion is generally greater than a project [12].

Several studies have focused on the elements that are directly related to the success of projects $[15,16]$ and 
governance factor is mentioned as one of the key determinants of project' success [17-19]. As argued by Musawir et al. [16], effective project governance enhances project success and enables the realization of strategic objectives through projects. However, governance in the particular context of universityindustry R\&D collaborations appears to be scarcely discussed in literature.

According to Project Management Institute [14], portfolio, program and project governance can be defined as the structure, processes and functions according to which project management activities are oriented to create the project result (product, process or service), which, in turn, should be in accordance with the strategic and operational objectives of the organization.

As well-recognized by professionals and academics the characteristics of a company's internal and external contextual environments needs to be taken into account in its design, in order to improve its performance, i.e. to establish environment-structure-strategy fit - contingency theory [20]. This theory has been widely applied in the area of project management [20].

Therefore, this paper aims to make a contribution in the field of governance in the particular context of universityindustry collaborations, by proposing a conceptual framework to support the governance of these collaborations. More specifically, this paper seeks to answer the following research question (RQ): What are the key organizational enablers to the governance of collaborative university-industry $R \& D$ programs?

To address this research question, the authors delved into a longitudinal collaborative case study between University of Minho (UMinho) and Bosch Car Multimedia (Bosch) in Portugal. Bosch and UMinho have different cultures and therefore different aims and motivations in the research program. This case entails two embedded collaborating programs: HMIExcel and IC-HMI composed by 14 and 30 projects, respectively. The two programs were conducted over a period of six years, from 2013 to 2018 , each one lasting for three years, with a total investment of more than 70 million Euro, partially financed by an external entity, the Portuguese Government.

The paper follows a common structure, where the second section addresses the concepts of Governance and Organizational enablers through a review of the literature on these topics. The third section describes the research methodology applied in this study. The fourth section specifies and discusses the results obtained for the research question. Finally, the conclusions and suggestions for future work are discussed.

\section{THEORETICAL BACKGROUND}

\section{A. University-Industry Collaborations}

In fast changing knowledge economies, industries exploit new sources of knowledge through collaboration with universities [21]. Long-term university-industries collaborations (UICs) are being used to stimulate and foster economic growth by bridging the gap between science and industry [22].

One of the main barriers to the effective management of UICs lies in the fact that university and industry organizations are guided by different incentive systems, based on motivations and self-values that lead to conflict of interests [23]. The success of UICs can be challenged due to the incompatibilities between the aims, limitations and priorities of university-industry collaborators [7].

Many collaborations are single projects with well-defined objectives and potential benefits. Commonly, such collaborations involve the management of a set of related projects, managed as a program of $R \& D$ projects over a prolonged period and aimed at achieving a broader set of strategic benefits often different than the sum of the individual projects [12]. UICs programs are based on interactive relationships that require considerable trust [24] and commitment between partners to create mutual benefits over time [25]. UICs require high commitment from all partners to assure that benefits are harmonized and consolidated [26].

With the increasing prevalence of collaborative $R \& D$ projects, as the particular form of university-industry interactions [13] [27], and their importance to the future success of both organizations and national economies, it is essential to develop new approaches and frameworks to address the collaboration challenges [5]. In fact, the specific context of UICs, through large and complex contracts funded by an external entity, with multiple partners and stakeholders with different cultures and mind-sets, has several specificities that require particular attention namely in governance.

At first it may appear that governing an interorganizational $\mathrm{R} \& \mathrm{D}$ project or program between university and industry is no different from project governance in a single organization, however there are additional challenges to be addressed with a university-industry consortium structure [28], which demands a strong research effort to produce effective guidelines.

\section{B. Organizational, Program and Project Governance}

According to OECD [29], there are four principles involved in good corporate governance: transparency (the accurately and timely disclosure of information); accountability (the clear understanding of roles and rights); responsibility (task execution within the standards of society); fairness (regarding moral and ethical principles).

In the existing literature there is no consensus for the definition of project governance [30]. Governance of individual projects should be aligned and based on organizational governance, since the principles of organizational governance influence projects through project governance [18]. In this way, project governance is the link between organizational governance and project management. Project Management Institute (PMI) [14] refers to project governance as a comprehensive and consistent project control method that is aligned with the organization's governance model and encompasses the project life cycle, ensuring its success and where there is the alignment of the project objectives with the organization's strategy.

While project governance deals with the governance of individual projects, other types of governance examine a group of projects, such as a program or portfolio of projects, and therefore have a broader perspective [31] and all of these elements (project, program and portfolio governance) should be placed together to co-exist within the organizational Governance [32]. Thus, according to PMI [14], program governance refers to the process of communication, implementation, monitoring, development and assurance of 
procedures, organizational structures, practices and policies associated with a particular program. That is, program governance comprises the system of values, responsibilities, policies and processes that enable projects to achieve organizational goals and promote project execution that satisfies all internal and external stakeholders and the organization itself [32].

Governance differs from management, since governance ensures that the business is executed efficiently and in the right direction, while Management runs the business [33]. Creating and maintaining sustainable value for the organization and its stakeholders requires a good governance structure [34]. According to the Association for Project Management (APM) [31] study, among project success factors adequate project governance has the strongest and most consistent relationship with all dimensions of project success. Moreover, failures in project governance are considered one of the most likely causes of project failure [35], in projects of all sizes, including large-scale projects [36].

\section{Governance Organizational Enablers}

An enabler can be defined as something that gives strength, power or competence to a particular purpose, making it efficient or capable [37]. In an organizational context, factors or circumstances that enable certain phenomena, such as well-established governance, are usually defined as organizational enablers (OEs). Without these, a specific phenomenon would not exist, or at least not in the same way [32].

In this sense, the OEs for governance are the interaction and coexistence of mental and structural elements, which together allow the occurrence of a specific phenomenon within a social structure [38]. OEs are composed of a synergy of the most objective elements of governance and the cultural and cognitive dimensions (ideology, relationship, values, ethics, morals, etc.) that allow governance to occur. They should be part of the social structures of project governance, including normative and behavioral systems [39]. According to PMI [14], OEs are human, cultural, structural, and technological practices that can serve to sustain strategic objectives. Thus, OEs are distinct from triggers and are seen as recognizable elements, such as policies or project management offices (PMOs), which are precedents of particular ways through which governance is performed [39].

Several OEs for project governance were identified in the literature: flexibility of organization structures [38], [39]; existence of framework and governance policies [38]; presence of specialized project governance functions (e.g., PMOs) [38]; and standardization of project management methodologies throughout the organization, strategic alignment of projects with business, steering groups, PMOs, defined roles, planned meetings, and top management support [39].

Muller, Pemsel and Shao [38] conceptualize OEs as comprising of process facilitators and discursive abilities, each with its own factors and mechanisms. Discursive abilities is the ability of organizational agents to articulate and construct the world, its legitimacy and knowledge, as well as the means for building meaning in organizations such as social interactions, ideologies, organizational legacy, and adapt the interpretation of each other's reality [39]. Process facilitators, are linked to organizational structures, policies, routines and practices, all of which allow the emergence of results, specific approaches to governance, and also support the achievement of organizational goals [39]. More specifically, the 'factors of discursive abilities' contemplate interactional and communicative characteristics that impact on the people's attitudes, such as support of top management or organizational culture. 'Factors of process facilitators' are constituted by conditions, tangible characteristics and variables that directly influence the efficiency, effectiveness and viability of governance, such as the formalization of procedures in the project governance or the degree of the client involvement. 'Mechanisms of discursive abilities' are discourse support structures and organizational sense-support structures, such as synchronized communication structures, dedicated network structures, rules and regulations, and so on. 'Mechanisms of process facilitators' concern the means to increase the likelihood of certain outcomes, such as structures, rules, informal routines of the organization, meetings, etc. [38]. Thus, the four elements of OEs (factors, mechanisms, process facilitators, and discursive abilities) are distinct in the means, powers, and levels at which they act, yet all aim to achieve a desired outcome [38].

The OEs are linked to the three pillars of institutional theory: normative, regulative and cultural-cognitive [39]. These pillars are defined by institutional theory to facilitate understanding of the stability and meaning of social life in organizations [40]. Normative elements include values, standards, formal and informal roles and formal and informal norms. Regulative elements involve laws, property rights and formal regulations, often imposed externally to the organization, usually materialized by means of relational contracts, adaptation to environmental laws, public-private partnerships, etc. [40, 41]. Finally, cultural-cognitive elements involve shared beliefs, symbols, shared action logics, and identities [42, 43].

As emphasized earlier one element that is considered to be an $\mathrm{OE}$ in one context may not be in another context, as they vary according to the perspective of an organization [44], therefore, despite some existent literature on the OEs for project governance $[38,39]$, research works on the OEs for governance of university-industry R\&D collaborations programs were not found. OEs also vary according to the governance level, for example, an $\mathrm{OE}$ for the governance of a single project may not be considered an $\mathrm{OE}$ for the governance of programs or portfolios. In the governance of a single project, more structural enablers prevail, such as policies, methodologies, guidelines and methods for executing governance. However, when considering the governance of programs, the number of people involved, their organizational visions and their values become more important [38].

Despite the differences that exist in OEs depending on the governance level, there is a common characteristic that prevails in the various levels, which is flexibility. In the governance of a single project there must be flexibility in methodologies and processes to address the different particularities of individual projects. In the governance of several projects- programs or portfolios, flexibility in organizational structures and in the understanding and attitude of all stakeholders in relation to work is also very important, such as flexibility in people's willingness to adapt to changes in tasks, goals and deadlines. Thus, flexibility is a key feature of successful governance at different levels [38]. 


\section{CASE STUDY}

Case study is perceived by researchers as one of the most used research strategies when context is particularly relevant [45]. By using it, researchers can focus on a particular phenomenon and discover crucial knowledge [46].

\section{A. Case Study Description}

In 2013 the University of Minho (UMinho) and Bosch Car Multimedia (Bosch) in Portugal embarked on a major university-industry collaboration program co-funded by Bosch, UMinho and the Portuguese government. The collaboration comprised two distinct programs. The first program involved 14 individual multidisciplinary $R \& D$ projects and the second program involved 30 individual $R \& D$ projects. The main science and technology domains were: electronics and instrumentation, information technology, mechanical technologies and materials, industrial engineering and management, and optical physics.

The first program was executed from May 2013 to June 2015 and involved an investment of $€ 19.2$ million. All the 14 projects occurred in parallel and involved 300 researchers. The program resulted in 12 registered patents, 32 scientific publications and 162 deliverables (technical reports and prototypes). The second program involved $30 \mathrm{R} \& \mathrm{D}$ projects from July 2015 to August 2018 and an investment of $€ 54.7$ million, involving around 500 researchers. The second program resulted in 417 deliverables, the submission of 22 patent applications and 72 technical and scientific publications. The program set of benefits resultant from the different interrelated projects' outputs, was reported on Fernandes, Pinto, Araújo and Machado [47].

\section{B. Data Collection and Analysis}

The actualities and lived challenges of a collaborative organization were analyzed in a four year in-depth research case study. From June 2014 to August 2018, the insider or fieldworker [48] closely followed the collaborative program, spending an average of two days per week in the program's context. During this period, the insider had their own physical workplace at the office, close to the PgPMO team, and had physical access to all collaborating parties. This enabled the researcher to interact freely with different internal stakeholders in naturally occurring situations, namely during technical meetings and regular management, and with program decision makers in various ways. Several written field notes were prepared during the participation observations. Each of the notes consisted of numerous informal interactions with the staff during the day and related reflections. The other authors acted as outsiders who reflected on observations from a distance [48], as well as on the analysis of several documents, namely the governance model established in both programs, status and performance reports, lessons learned register, and even deliverables, in order to better understand the case study context.

Based mainly on the works of Muller et al. [38, 39] a preliminary code list about the governance phenomenon was developed. This list was used as a blueprint for conducting the data analysis. The field notes and the previously mentioned documents were scanned by the authors and the results were discussed, among them, to identify the OEs for the governance in the context of collaborative R\&D UniversityIndustry Programs.
Observation is often criticized for a potential lack of reliability [46] however, it is an important holistic research method, which enables the researchers to gain a better understanding of the insider's perspective [49].

\section{RESUlTS AND DiscUSSION}

\section{A. Organizational Enablers Conceptual Framework}

This section presents the developed conceptual framework for enabling the governance of collaborative UniversityIndustry $R \& D$ programs based on the four years of observations of the case study between Bosch Car Multimedia in Portugal and University of Minho and the OEs identified in literature, mainly in the works of Muller et al. [38, 39] (see TABLE I). In 2014, Muller et al. [38] from a structured literature review identified OEs for governance of projects. Later, in 2015, through a multiple case study with six companies in Sweden and China, the authors [39] identified OEs, using the institutional theory as theoretical perspective. Both works of Muller et al. [38, 39] were carried out in a context of project-based organizations.

Project-based organizations use projects as a way of doing business, that is, they are autonomous organizations or subsidiaries of a larger corporation that recognize the work of the project and perform most of their activities through projects or even use projects as strategic means for differentiation [50]. University-Industry R\&D partnerships might be understood as a project-based organization, as the partnership aims to carry out several programs or projects between the two entities, as means of achieving their organizational objectives, where the governance of the new established projects and programs are influenced by the organizational governance of university as well as the organizational governance of industry (see Fig. 1).

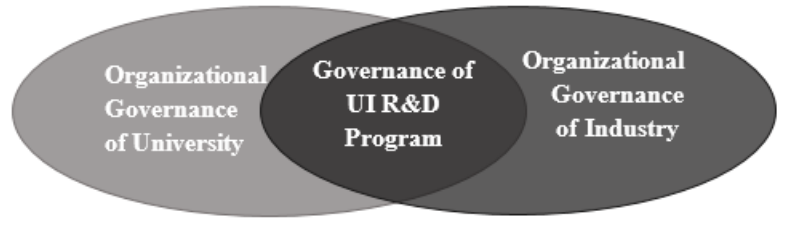

Fig. 1. Governance of the collaborative R\&D university-industry program.

TABLE I. OES FOR GOVERNANCE OF COLLABORATIVE R\&D UNIVERSITYINDUSTRY PROGRAMS

\begin{tabular}{|l|l|}
\hline Organizational Enabler & Theoretical Background \\
\hline $\begin{array}{l}\text { Formal governance support } \\
\text { structures }\end{array}$ & $\begin{array}{l}\text { Steering groups and PMOs [39] } \\
\text { Presence of specialized project } \\
\text { Governance roles [38] }\end{array}$ \\
\hline Flexible organization structures & $\begin{array}{l}\text { Flexibility in structures and } \\
\text { interactions [38] } \\
\text { Flexible organization structures } \\
\text { [39] }\end{array}$ \\
\hline $\begin{array}{l}\text { Standardization of program and } \\
\text { project management practices }\end{array}$ & $\begin{array}{l}\text { Standardization Company-wide } \\
\text { methodologies [39, 51] }\end{array}$ \\
\hline $\begin{array}{l}\text { Established governance policies } \\
\text { and values }\end{array}$ & $\begin{array}{l}\text { Governance frameworks and } \\
\text { policies [38] }\end{array}$ \\
\hline $\begin{array}{l}\text { Clearly defined roles and } \\
\text { responsibilities }\end{array}$ & Clearly defined roles [39] \\
\hline $\begin{array}{l}\text { Different management approaches } \\
\text { to fit the project needs }\end{array}$ & $\begin{array}{l}\text { Project management } \\
\text { methodologies [39] }\end{array}$ \\
\hline Top management support & Top management support [39] \\
\hline $\begin{array}{l}\text { Projects strategic alignment within } \\
\text { industry and university } \\
\text { roadmaps }\end{array}$ & $\begin{array}{l}\text { Alignment of projects and } \\
\text { business [39] }\end{array}$ \\
\hline $\begin{array}{l}\text { Different of } \\
\text { communication and interaction }\end{array}$ & $\begin{array}{l}\text { Flexibility in structures and } \\
\text { interactions [38] }\end{array}$ \\
\hline \multicolumn{2}{|c|}{ and } \\
\hline
\end{tabular}


Fig. 2. presents the nine OEs identified to facilitate the governance of collaborative R\&D University-Industry programs. These are subsequently discussed by their categorization under the three pillars of institutional theory, normative, regulative and cultural-cognitive [39].

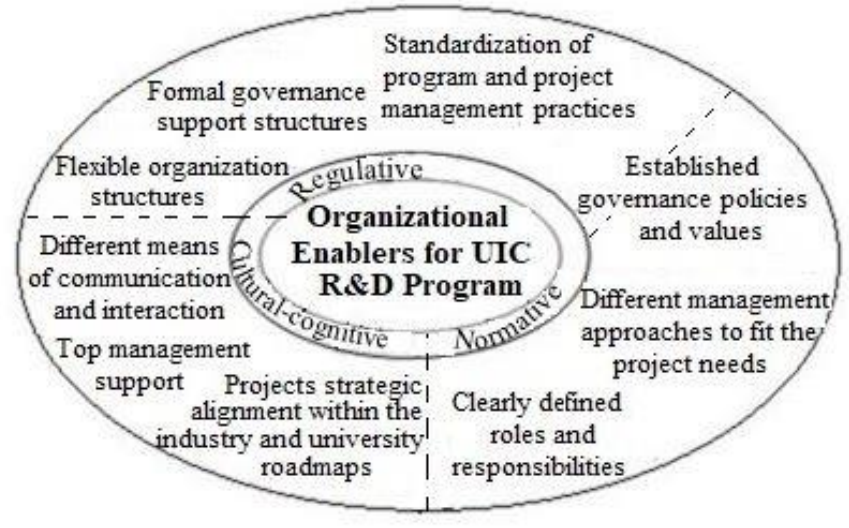

Fig. 2. Conceptual framework for enabling the governance of collaborative R\&D University-Industry Programs

\section{B. Regulative Organizational Enablers}

As shown in Fig. 2 three OEs were identified in the regulative pillar of the institutional theory: 'Formal governance support structures', 'Flexible organization structures' and 'Standardization of program and project management practices'.

UMinho and Bosch have invested in a 'Formal governance support structure' of the type Project Management Office named Program and Project Management Office (PgPMO). The PgPMO has a serving role [52], since its main objective is to support both the Program Coordination and Project Teams during the program and project management life cycle. Fig. 3 presents the Bosch and UMinho organization structure to support the collaborative R\&D program (grey boxes,) as well as the formal communication (colored arrows).

The Program Coordination is composed of four people: two Program Directors, one from UMinho and another from Bosch, and two Program Managers, one of each institution, as well. In fact, each program organization role has always a representative from Bosch and another from UMinho. The Program Coordination is the organism responsible to guarantee the program benefits realization. Above Program Coordination is the Steering Committee, supported by an Innovation Management Team, and the Guidance and Supervision Council. The Guidance and Supervision Council involves a third party beyond a representative from UMinho and Bosch, which has as main function to solve potential conflicts that might arise, and that both members are not able to solve alone due to potential conflicts of interests.

Although the organization structure adopted by UMinho and Bosch collaboration looks hierarchical (Fig. 3), in fact it was a very 'Flexible organization structure' when we looked to the different means used by the different elements to communicate. They use not only formal channels, but often informal channels. Informal communication aims at meeting personal needs, such as interacting with others, influencing the behavior of others and being a means of passing information about work, which through formal channels would not be possible. It is seen as an unofficial communication network that complements the formal channels. It presents a set of advantages such as agility of execution and communication supported by the trust between the stakeholders. Despite this, it is important to note that informal communication cannot replace formal communication, as it is fundamental in many situations throughout the program and project management life cycle [14].

Regarding the formal communication existing in Bosch and UMinho collaborative programs, this is done according to the hierarchical relations present in the organizational structure (Fig. 3). Thus, basically, communication is done in a downward manner between a higher body and the other organs that are hierarchically immediately below, to implement strategies, objectives, policies and procedures, give work instructions and give feedback on performance. Upwards communication is carried out from the lower bodies to the bodies that are immediately higher up to report problems, criticisms, performance reports, issues, complaints, disputes and give suggestions for improvement and needs. In addition to these two channels (ascending and descending) there is also the horizontal channel that corresponds, for example, to the exchange of information between different Project Teams, to solve interdependent project problems, advice and feedback.

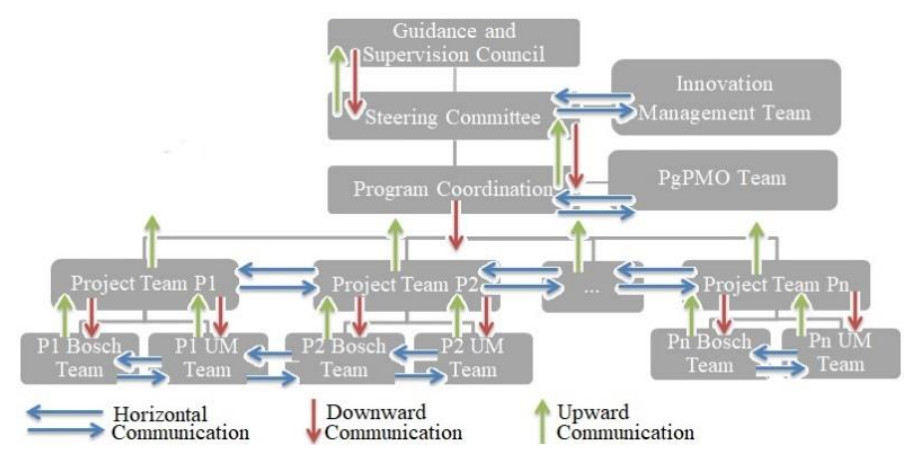

Fig. 3: Program organization adopted in both programs and formal communication.

Regarding the informal communication, represented in Fig. 4, it can be carried out basically between any of the elements included in the organization structure. This occurs through various means, such as through social networks, telephone contact and personally, namely during the several conducted events of dissemination and sharing results, where common elements of different hierarchical levels freely communicated among them.

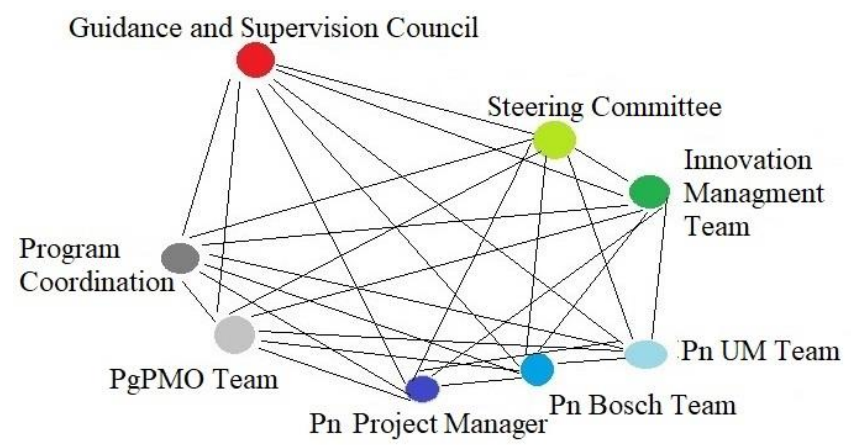

Fig. 4. Informal communication.

Bosch and UMinho have perceived the value of project management to support the management of both R\&D programs; and therefore, have made the 'Standardization of program and project management practices' based on a 
purposely developed approach especially devoted to program and project management of collaborative University-Industry R\&D funded contracts, named PgPM approach [53]. The PgPM approach for collaborative university industry $R \& D$ funded contracts establishes a project management layer bellow the layer of the program management, and a common and consistent set of management phases is being established (see Fig. 5), including several key program and project management processes and practices standardized for each phase.

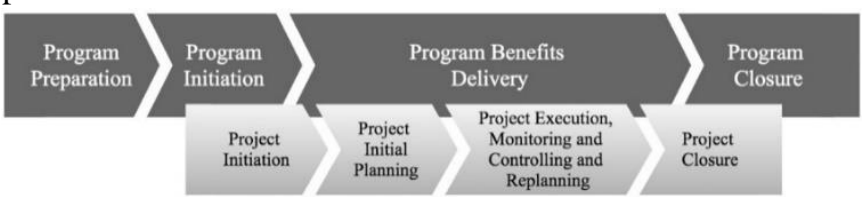

Fig. 5. Program and project management phases.

In brief, Bosch and UMinho R\&D collaboration adopted a program management life cycle divided into four phases: 1) Program Preparation: to align a common strategy of Bosch and UMinho, to identify the program scope, and to strive for the necessary resources to support new $R \& D$ projects in the program, such as the financial support for the program by the national Government (funding application); 2) Program Initiation: to guarantee the initial planning of the program and the alignment of the program objectives and outcomes with the stakeholders that will effectively get involved into the program execution; 3) Program Benefits Delivery: throughout this iterative phase, the projects of the program are planned, integrated and managed to facilitate the delivery of the intended program benefits; 4) Program Closure: to execute a controlled closure of the program and determine if the collaboration can be sustained.

The project management life cycle layer is divided also into four phases: 1) Project Initiation: to carry out the project kick-off supported by the project charter artefact, which creates the project linkage with the objectives established in the program application proposal for national funding; 2) Project Initial Planning: to reach a compromise between the program management and the project team of the initial project plan (includes scope, time, cost, and quality and benefits); 3) Project Execution, Monitoring and Controlling, and Re-planning: to execute the project work, to monitor and take the necessary control actions to pursue project success; 4) Project Closure: to produce the project closing report, to obtain formal acceptance of the results by stakeholders, to formalize the handover of the project results, and to archive all project information, namely the collected lessons learned.

\section{Normative Organizational Enablers}

Governance is a system of policies, values, responsibilities and processes [38] and therefore there is the necessity to well establish them. Fig. 2 shows 'Clearly defined roles and responsibilities' and 'Different management approaches to fit the project needs' as two normative OEs, and additionally the OE 'Established governance policies and values' that is seen in both normative and regulative pillar. Policies are regulative and values are more normative [39].

In the case of Bosch and UMinho collaborations the processes, roles and responsibilities were well-established at the document named Governance Model. However, policies and values were not explicitly defined.
Therefore, based on governance literature review and the four years of the case study observation, the researchers identified some of the most cited policies to be established during university-industry R\&D collaborations, namely:

- Balanced leadership between university and industry partners.

- Existence of at least one element of each partner in the different organs of the organization structure, for example a program manager for the industry partner and a program manager for the university partner.

- Recognition of only one point of accountability.

- Differentiation between the Governance structures of the university-industry collaborative $R \& D$ program and the organizational governance of partners.

- A transversal governance model.

Additionally, in terms of leadership, in the case study of Bosch and UMinho collaborations, the insider researcher saw mostly a vertical leadership. Complete emphasis was placed on the project manager leader which took the majority of the decisions. However, this typology of university-industry collaborative R\&D programs and projects might benefit also in some occasions from horizontal leadership, where there is less participation of the leader and decisions are taken mostly by the remaining team [54]. For horizontal leadership it is required a fairly high level of maturity in interpersonal relationships, as well as efficient communication and experienced professionals for decision making.

Regarding values, these relate to a set of characteristics that will determine how the various elements that are part of the governance structure should behave, that is, they reflect the way in which all work should be carried out, such as the program and the various projects are managed, as well as professional ethics when dealing with business partners [39]. During the four years of in-depth observations the most frequently mentioned values listen by the insider researcher were:

- Focus on the necessary competencies of all those involved (researchers and industry collaborators) in $\mathrm{R} \& \mathrm{D}$ activities.

- Educate and be educated.

- Team spirit. The project team should see itself as a team and not just as a group of people, so it is necessary to have common goals and that all members act towards achieving these goals through working as a team, sharing and mutual support, group responsibility and self-criticism.

- Economic, environment and social sustainability, ensuring the needs of the present without compromising those of future generations, as well as fostering the sustainability of the university and industry partnership.

- Equity and inclusion, which implies dealing fairly with all stakeholders involved, as well as to ensure that everyone feels they are an important part of the program or project.

- Efficiency and effectiveness in the production of results and the generation of benefits for both university and industry and also to society.

The Governance Model document 'Clearly defined roles and responsibilities' existent in the UMinho and Bosch 
collaborative R\&D program governance structure: Guidance and Supervision Council, Steering Committee, Program Coordination, Program Director, Program Manager, Project Manager, Team element, the Innovation management Team, and PgPMO, including the detail of the four different roles existent in the PgPMO structure (PgPMO Officer, PgPMO Finance, PgPMO Communication and PgPMO Quality Management Assurance) described by the different phase of the program and project management life cycle.

Bosch and UMinho collaboration also recognized the importance of having 'Different management approaches to fit the project needs', therefore a hybrid project management approach was implemented. This hybrid approach identified in the Governance Model document a set of Must Have project management practices, transversal to all projects in the program, as the practices that the program governance must assure, for example the Project Charter or the monthly Project Progress Meetings with the PgPMO Officer. Additionally, it identified three different sets of Nice to Have project management practices, which are optional and are dependent on the particular project context and project management approach adopted by each project team, waterfall or agile, as shown in Fig. 6 bellow.

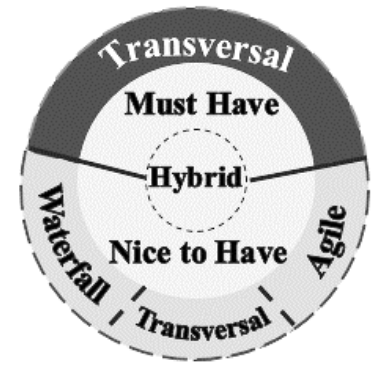

Fig. 6. Hybrid approach for managing collaborative university-industry R\&D from [55].

One of the most used practices across the program and project management phases, and recognized by the different stakeholders as very important, were the different Meetings scheduled at both program and project management level. At the program level:

- Alignment Meetings between both university and industry partners in order to establish the scope of projects in the program.

- Preparation Meeting for the clarifications required by the funding application evaluators, assured by the Program Directors, Program Managers and responsibles for Project Ideas.

- Steering Committee Meetings to discuss and approve, namely the governance model, the rules of formation of the Teams for each project and the effective start date of the work of the program.

- Program Kick-off Meeting for the formalization initiation of the program.

- PgPMO Meetings between the PMO Officers of Bosch and UMinho, with the objective of discussing the effective progress of the work of the different projects and the continuous improvement of the Governance Model established for the programs.

- Program Coordination Meetings, namely for the discussion of the Program's Monthly Performance
Report, in order to ensure alignment between Program Managers and the PgPMO Team.

At the project level, there were several Must Have Meetings, such as:

- Alignment Project Stakeholders Meetings, which aim to ensure the understanding of the interdependencies between the projects within the program and align stakeholders' expectations.

- Kick-off Meeting of the project, which is the formalization meeting of the initiation of the project.

- Progress Meetings, which are the main practice for monitoring and control of the project, with a welldefined agenda and from which the Project Progress Reports result.

- Workplace Meetings, held at every six months and occurring at project development sites, where project results to date are presented and shared by Project Managers to key project internal and external stakeholders.

- Project Closure Meeting to formally close the project and discuss the main project lessons learned retained.

\section{Cultural-Cognitive Organizational Enablers}

As shown in Fig. 2 three OEs were identified in the cultural-cognitive pillar of the institutional theory: 'Top management support', 'Projects strategic alignment within the industry and university roadmap' and 'Different means of communication and interaction'.

'Top management support' is well-recognized in project management literature as a key critical project success factor [56] and played an important role in the governance of Bosch and UMinho collaborations. These collaborations had the direct support of the University Dean and the Board of Directors of Bosch; both had a seat at the Steering Committee of both collaborative R\&D programs. The Board of Directors of Bosch actively sponsored each project, namely by participating regularly in the projects' workplace meetings, encouraging the participation/ involvement of all stakeholders in pursuing the projects' objectives.

The 'Projects strategic alignment within the industry and university roadmap' should be taken into account since the Program Preparation phase, where the Funding Application has been prepared for submission, therefore the Alignment Meetings between the university and industry partners are crucial in this process. During the Program Initiation phase it is also critical the Alignment Project Stakeholders Meetings to ensure the understanding of the interdependencies between the projects within the program, besides the contribution to the creation and growth of a project's team spirit, since it is common that people are working together for the first time. Furthermore, the transition between the submission of the Funding Application (Program Preparation phase) and its approval and Investment Contract's sign-off (Program Initiation phase) may exceed a year period. Accordingly, this considerable temporal lag somehow favors administrative and financial misalignments and technological market trends shifts. Therefore, the Alignment Stakeholders Meetings also aim to (re)align Project Managers' expectations and objectives.

In the case study Bosch and UMinho collaborations, it was observed 'Different means of communication and 
interaction'. Good communication and the existence of different channels and means of communication is extremely important for the success of a program or project, since one of the major causes of project failure is related to communication failures [57]. The communication tools most used by the program's internal stakeholders are: a document management system from Bosch, made available for all internal stakeholders, including university stakeholders, as the formal shared workspace to access all information about the program and projects; Outlook; Skype and the mobile phone. Fernandes et al. [58] analyzed each tool used, in terms of their communication's direction, potential and effective uses, and their benefits and issues associated with their usage, as well as the several communication issues identified during the observation of the Bosch and UMinho case study. Among these issues geographical barriers were identified, since project team members are distributed over different geographic locations. This factor brings some issues, related with travelling and bringing up the need for information accessibility anywhere and anytime. Note that to facilitate communication between program team members a physical room was created for Bosch-UMinho partnership, both in Bosch and in UMinho headquarters, designed to receive the elements of the Program Team whenever they move between the two institutions.

Bosch and UMinho case study had established a communication plan divided into internal, external communication and external communication in media. The first one includes the exchange of information between the Program Team, which is done for example through the Program and Project Progress Reports, with the support of the PgPMO Officer role. External communication is the responsibility of the PgPMO Communication member and concerns the information exchanged between the Program Team and beyond the Program Team, i.e. the external public. It has as main communication mechanisms: events of dissemination and sharing of results, newsletters, brochures, magazine, among other merchandising products. The external communication in the media is outside the scope of the communication plan and is therefore of the responsibility of the Communications Office of Bosch and the Office of Communication and Image of UMinho. This refers to the communication disseminated in the channels of public dissemination (TV, radio and written press).

\section{CONCLUSIONS}

The main contribution of this study is the conceptual framework for enabling the governance of UniversityIndustry R\&D programs (see Fig. 2). The conceptual framework identifies the key Organizational Enablers (OEs), which can provide guidance to universities and industries interested in establishing governance models as main mechanism to enhance the benefits resultant from universityindustry R\&D collaborations initiatives.

Based mainly in works from Muller et al. [38, 39] and the observation during four years of the case study of Bosch Car Multimedia in Portugal and University of Minho, nine OEs for Program Governance were identified and categorized into the three pillars of institutional theory (regulative, normative and cultural-cognitive pillars) [39]. In the regulative pillar we identified 'Formal governance support structures', 'Flexible organization structures' and 'Standardization of program and project management practices'. In the normative pillar we identified 'Clearly defined roles and responsibilities' and 'Different management approaches to fit the project needs' as two normative OEs, and additionally the OE 'Established governance policies and values' that is seen in both normative and regulative pillar. Finally, 'Top management support', 'Projects strategic alignment within the industry and university roadmap' and 'Different means of communication and interaction' were three OEs identified in the culturalcognitive pillar.

Like any framework, the conceptual framework for the governance of collaborative R\&D University-Industry programs portrays a partial and incomplete view of reality and should therefore be used cautiously by university and industry on designing the governance structure, considering how the temporary organization structure should work during its evolution throughout the program life cycle [59, 60].Additionally, as any research based on a case study, it has limitations on the generalization of results. The results are induced from one case and might thus be contingent upon its special context, and the reasoning may be influenced by random factors. In this regard, future research can benefit from multiple case studies, allowing for cross-checking the conclusions among them.

\section{ACKNOWLEDGMENT}

This work is financed by National Funds through the Portuguese funding agency, FCT - Fundação para a Ciência e a Tecnologia within project UIDB/50014/2020.

\section{REFERENCES}

[1] P. Tumbas, P. Matkovic, M. Maric, V. Pavlicevic, "Organizational Aspects of University-Industry Collaboration," in EDULEARN16. 2016. Barcelona, Spain

[2] J. Berbegal-Mirabent, J.L. Sánchez García, and D.E. Ribeiro-Soriano, University-industry partnerships for the provision of R\&D services. Journal of Business Research, 2015, 68(7), pp. 1407-1413.

[3] V. Galan-Muros, and T. Davey, "The UBC ecosystem: putting together a comprehensive framework for university-business cooperation," The Journal of Technology Transfer, 2017, 44(4), pp. 1311-1346.

[4] N. Salimi, R. Bekkers, and K. Frenken, Governance and success of university-industry collaborations on the basis of $\mathrm{PhD}$ projects-an explorative study. Eindhoven Center for Innovation, 2013.

[5] C.M.M. Chin, E.H. Yap, and A.C. Spowage, "Project Management Methodology for University-Industry Collaboration Projects Review of International Comparative Management," 2011, 12(5), pp. 901918.

[6] S. Ankrah and O. Al-Tabbaa, "Universities-industry collaboration: A systematic review," Scandinavian Journal of Management, 2015, 31(3), pp. 387-408.

[7] T.A. Barnes, I.R. Pashby, and A.M. Gibbons, "Managing collaborative $\mathrm{R} \& \mathrm{D}$ projects development of a practical management tool," International Journal of Project Management, 2006, 24(5), pp. 395-404.

[8] Y.S. Lee, "The Sustainability of University-Industry Research Collaboration: An Empirical Assessment," The Journal of Technology Transfer, 2000, 25(2), pp. 111-133.

[9] M. Perkmann and K. Walsh, "University-industry relationships and open innovation: Towards a research agenda," International Journal of Management Reviews, 2007, 9(4), pp. 259-280.

[10] D. Mindruta, "Value creation in university-firm research collaborations: A matching approach," Strategic Management Journal 2013, 34(6), pp. 644-665.

[11] C. Biesenthal and R. Wilden, "Multi-level project governance: Trends and opportunitiesm," International Journal of Project Management, 2014, 32(8), pp. 1291-1308.

[12] S. Pellegrinelli, "What's in a name: Project or programme?," International Journal- of Project Management., 2011, 29(2), pp. 232240 . 
[13] J.v. Brocke and S. Lippe, "Managing collaborative research projects: A synthesis of project management literature and directives for future research," International Journal of Project Management, 2015, 33(5), pp. 1022-1039.

14] Project Management Institute, A Guide to the Project Management Body of Knowledge $6^{\text {th }}$ ed. Pennsylvania: Project Management Institute, Inc, 2017.

[15] A. Badewi, "The impact of project management (PM) and benefits management $(\mathrm{BM})$ practices on project success: Towards developing a project benefits governance framework," International Journal of Project Management, 2016, 34(4), pp. 761-778.

[16] A. Musawir, C.E.M. Serra, O. Zwikael, A. Imran., "Project governance, benefit management, and project success: Towards a framework for supporting organizational strategy implementation,' International J. of Project Management, 2017, 35(8), pp. 1658-1672.

[17] R. Joslin, and R. Müller, "Relationships between a project management methodology and project success in different project governance contexts," International Journal of Project Management, 2015, 33(6), pp. 1377-1392.

[18] R. Joslin, and R. Müller, "The relationship between project governance and project success," International Journal of Project Management, 2016, 34(4), pp. 613-626.

[19] T.G. Lechler, and D. Dvir, "An Alternative Taxonomy of Project Management Structures: Linking Project Management Structures and Project Success," IEEE Transactions on Engineering Management, 2010, 57(2), pp. 198-210.

[20] B.Hanisch, and A. Wald, "A bibliometric view on the use of contingency theory in project management research," Project Management Journal, 2012, 43(3), pp. 4-23.

[21] Scandura, A., "University-industry collaboration and firms' R\&D effort," Research Policy, 2016, 45(9), pp. 1907-1922.

[22] M. Perkmann, Z. King, and S. Pavelin, "Engaging excellence? Effects of faculty quality on university engagement with industry," Research Policy, 2011, 40(4), pp. 539-552.

[23] J. Bruneel, P. D’Este, and A. Salter, "Investigating the factors that diminish the barriers to university-industry collaboration," Research Policy, 2010, 39(7), pp. 858-868

[24] C. Plewa, N. Korff, T. Baaken, G. Macpherson, "University-industry linkage evolution: an empirical investigation of relational success factors," R\&D Management, 2013, 43(4), pp. 365-380.

[25] C. Plewa, "Key drivers of university-industry relationships: the role of organisational compatibility and personal experience," Journal of Services Marketing, 2007, 21(5), pp. 370-382.

[26] M. Perkmann, et al., "Academic engagement and commercialisation A review of the literature on university-industry relations," Research Policy, 2013, 42(2), pp. 423-442.

[27] P. Hanel and M. St-Pierre, "Industry-University Collaboration by Canadian Manufacturing Firms, "The Journal of Technology Transfer, 2006, 31(4), pp. 485-499.

[28] S. Peterson, "Consortia partnerships: Linking industry and academia," Computers \& Industrial Engineering, 1995, 29(1-4), pp. 355-359.

[29] OECD, The OECD principles of corporate governance. Paris: OECD Publishing, 2004.

[30] M.C. Bekker, Project governance: "Schools of thought". 2014, 17(1),p. 11.

[31] Association for Project Management, Conditions for project success. APM research report Princes Risborough: Association for Project Management, 2004,

[32] R. Müller, Project Governance (Fundamentals of project management). Gower Publishing, 2009.

[33] B. Ticker, Corporate Governance: Principles, Policies and Practices. 2nd ed. New York: Oxford University Press, 2012.

[34] I. Ruuska, T. Ahola, K. Artto, G. Locatelli, M. Mancini, "A new governance approach for multi-firm projects: Lessons from Olkiluoto 3 and Flamanville 3 nuclear power plant projects," International Journal of Project Management, 2011, 29(6), pp. 647-660.

[35] A. van Marrewijk, S. Clegg, T.S. Pitsis, M. Veenswijk, "Managing public-private megaprojects: Paradoxes, complexity, and project design," International Journal of Project Management, 2008, 26(6), pp. 591-600.

[36] P. Patanakul, "Managing large-scale IS/IT projects in the public sector: Problems and causes leading to poor performance," The Journal of High Technology Management Research, 2014, 25(1), pp. 21-35.

[37] Project Management Institute, Organizational Project Management Maturity Model (OPM3®) 3rd ed. Newtown Square, PA: Project Management Institute, 2013.
[38] R. Müller, S. Pemsel, and J. Shao, "Organizational enablers for governance and governmentality of projects: A literature review," International Journal of Project Management, 2014, 32(8), pp. 13091320.

[39] R. Müller, S. Pemsel, and J. Shao, "Organizational enablers for project governance and governmentality in project-based organizations," International Journal of Project Management, 2015, 33(4), p. 839-851.

[40] W. Scott, "Institutional Theory: Contributing to a Theoretical Research Program, in Great Minds" in Management: The Process of Theory Development, K.G. Smith and M.A. Hitt, Editors. Oxford University Press: Oxford UK, 2005

[41] W.J. Henisz, R.E. Levitt, and W.R. Scott, "Toward a unified theory of project governance: economic, sociological and psychological supports for relational contracting," Engineering Project Organization Journal, 2012, 2(1-2), pp. 37-55.

[42] V.F. Misangyi, G.R. Weaver, and H. Elms, "Ending Corruption: The Interplay among Institutional Logics, Resources, and Institutional Entrepreneurs," The Academy of Management Review, 2008, 33(3), pp. 750-770.

[43] R.J. Orr and W.R. Scott, "Institutional exceptions on global projects: a process model," Journal of International Business Studies, 2008, 39(4), pp. 562-588.

[44] S. Maitlis and T.B. Lawrence, "Triggers and enablers of sensegiving in organizations," Academy of Management Journal, 2007, 50(1), pp. $57-84$.

[45] R.K. Yin, Case Study Research: Design and Methods 6th ed. California, United States of America: Sage Publications, Inc., 2018.

[46] M. Saunders, P. Lewis, and A. Thornhill, Research Methods for Business Students 8th ed. Edinburgh: Pearson Education Ld., 2019.

[47] G. Fernandes, E.B. Pinto, M. Araújo, R.J. Machado, "Planning Benefits Realization in a Collaborative University-Industry R\&D Funded Program," in International Conference on Engineering, Technology and Innovation (ICE/ITMC), 2017,. Madeira, Portugal.

[48] J. Bartunek, and M.R. Louis, Insider/outsider team research (Vol. 40). Sage Publications, Inc., 1996.

[49] L.M Baker., "Observation: A complex research method," Library Trends, 2006, 55(1), pp. 171-189.

[50] L. Lindkvist, "Governing Project-based Firms: Promoting Market-like Processes within Hierarchies," Journal of Management and Governance, 2004, 8(1), pp. 3-25.

[51] G. Fernandes, D. O' Sullivan, E. B. Pinto, M. Araújo, R. J. Machado, "Value of project management in university-industry R\&D collaborations," International Journal of Project Management in Business, 2020, pp. 1-25

[52] G. Fernandes, E.B. Pinto, M. Araújo, R.J. Machado, "The roles of a Programme and Project Management Office to support collaborative university-industry R\&D," Total Quality Management \& Business Excellence, 2018, $31(5,6)$, pp. 583-608.

[53] G. Fernandes, E.B. Pinto, R.J. Machado, M. Araújo, A. Pontes, “A Program and Project Management Approach for Collaborative University-industry R\&D Funded Contracts," Procedia Computer Science, 2015, 64, pp. 1065-1074

[54] Müller, R., S. Sankaran, N. Drouin, A. Vaagaasar, M.C. Bekker, K. Jain, "A theory framework for balancing vertical and horizontal leadership in projects," International Journal of Project Management, 2018, 36(1), pp. 83-94

[55] G. Fernandes, S. Moreira, M. Araújo, E.B. Pinto, R.J. Machado, "Project Management Practices for Collaborative University-Industry R\&D: A Hybrid Approach," Procedia Computer Science, 2018, 138, pp. 805-814.

[56] J. Fortune and D. White, "Framing of project critical success factors by a systems model," International Journal of Project Management, 2006, 24(1), pp. 53-65

[57] R. Müller and K. Jugdev, "Critical success factors in projects: Pinto, Slevin, and Prescott - the elucidation of project success," International Journal of Managing Projects in Business, 2012, 5(4), pp. 757-775.

[58] Fernandes, G., C. Pessoa, A.R. Martins, E.B. Pinto, T. Ruão, M. Araújo, A.J. Pontes, R.J. Machado, “A Conceptual Social Media Tool for Supporting Collaborative University-Industry R\&D Programs," in CE/IEEE 2018 - International Conference on Engineering, Technology and Innovation. 2018. Stuttgart.

[59] R. Derakhshanalavijeh, G. Fernandes, and M. Mancini, "Evolution of Governance in a Collaborative University-Industry Program," Project Management Journal 2020 (in press).

[60] Patanakul, P., Y.H .Kwak., O. Zwikael, M. Liu, "What impacts the performance of large-scale government projects?", International Journal of Project Management, 2016, 34(3): pp. 452-466 